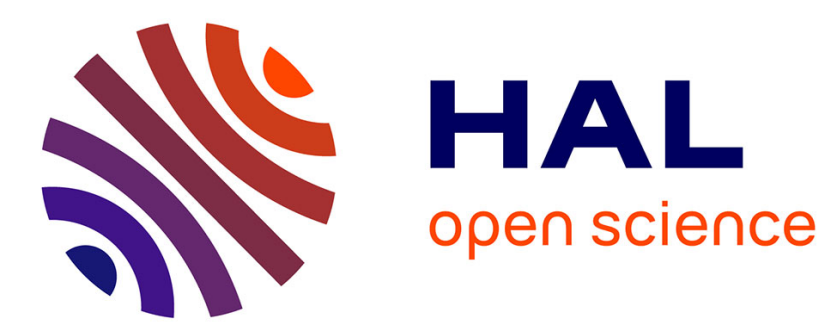

\title{
Physical mechanisms controlling keyhole and melt pool dynamics during laser welding \\ Remy Fabbro
}

\section{To cite this version:}

Remy Fabbro. Physical mechanisms controlling keyhole and melt pool dynamics during laser welding. Advances in Laser Materials Processing: Technology, Research and Application, Woodhead Publishing Limited, pp.211-241, 2010, 978-184569474-6. 10.1533/9781845699819.3.211 . hal-02619233

\section{HAL Id: hal-02619233 \\ https://hal.science/hal-02619233}

Submitted on 25 May 2020

HAL is a multi-disciplinary open access archive for the deposit and dissemination of scientific research documents, whether they are published or not. The documents may come from teaching and research institutions in France or abroad, or from public or private research centers.
L'archive ouverte pluridisciplinaire HAL, est destinée au dépôt et à la diffusion de documents scientifiques de niveau recherche, publiés ou non, émanant des établissements d'enseignement et de recherche français ou étrangers, des laboratoires publics ou privés. 


\title{
Physical mechanisms controlling keyhole and melt pool dynamics during laser welding
}

R. FABBRO, Arts et Metiers ParisTech/CNRS, France

\begin{abstract}
The aim of this chapter is to review our main recent understanding of physical mechanisms occurring during keyhole laser welding. The focus is on the analysis of melt pool dynamics showing that it is the interaction of the vapour plume emitted from the keyhole front with the melt pool that plays a dominant role in melt pool dynamics. Different specific regimes concerning the behaviour of the melt pool for a large range of welding speeds can be observed, and these regimes are precisely defined by the inclination of the keyhole front. A model taking into account these physical processes is proposed and allows us to describe the keyhole parameters and to understand these different observed results.
\end{abstract}

Key words: keyhole laser welding, melt pool dynamics, vapour plume interaction, keyhole geometry dynamics, keyhole modelling.

\subsection{Introduction}

The welding process is one of the most used laser processes in industry. Since the early 1970s the continuous development of this process has necessitated many studies throughout the world, motivated by the need to improve performance of welding of various materials, higher welding speeds, better quality and availability of new lasers. All these points have pushed many researchers to better understand the physical processes involved during laser welding. Fortunately, even if all these complex mechanisms are not completely understood, this laser application is obviously rather popular, but these constraints and needs are still present, and therefore necessitate a constant effort for improved understanding. The aim of this chapter is to review our main recent understanding of physical mechanisms of that process. Since the beginning of laser welding, an impressive amount of models, descriptions and physical process studies have been achieved. From the first simplified descriptions using thermal sources with more or less complex distributions inside or at the surface of the material, the studies have then involved laser beam interaction with vapour and/or plasma, and the corresponding effect of this coupling with keyhole geometry. These studies were mainly directed at obtaining an induced thermal field inside the solid, and much less attention 
has been devoted to a precise hydrodynamic description of the fluid flow occurring inside the melt pool. Obviously today, a complete mastering of the weld seam quality, as for example, the porosity formation process that is mainly controlled by the hydrodynamic phenomena, needs at least a complete understanding of the fluid flow field. Several qualitative effects were, however, described but no satisfying coupling between the physical processes inside the keyhole and the melt flow could be achieved. The lack of precise knowledge of the driving forces for fluid motion partly explains this situation. Also the use of hydrodynamic simulations and their numerical description is something that is a considerable task. It is only recently that significant simulations for solving Navier-Stokes equations were obtained, also taking into account laser-matter interaction with thermo-hydrodynamic effects, for a 3D geometry, with a non-stationary behaviour and free surface effects of the melt pool (Ki et al., 2002, Zang et al., 2002). Unfortunately, these complex simulations are still limited by the power of modern computers.

However, experimental observations are the main source for improving our knowledge. Experimental programs of melt pool dynamics study are therefore of crucial importance. Obviously, for several years the methodology adopted by Prof. Matsunawa of using melt pool X-ray shadowgraphy has been very efficient (Matsunawa et al., 1998). The different observations on keyhole and melt pool dynamics he made improved our understanding: generation of humps along the keyhole front, characteristic keyhole fluctuations, complex fluid flow of the melt pool, etc. The concept of 'drilling velocity' he developed with V. Semak (Matsunawa and Semak, 1997, Semak and Matsunawa, 1997) is essential for a correct description of these phenomena (one must note that this mechanism had already been mentioned several years before for the laser drilling (Von Allmen et al., 1976) or cutting process (Petring, 1995)). It is the basis of a simplified model that allowed us to reproduce numerically all the characteristic parameters of keyhole dynamics that will be discussed in Section 8.2.

It is well understood now that fluid flow in the laser melt pool is driven by several mechanisms. Even if the thermocapillary effect (or Marangoni effect) has been very often quoted (Furich et al., 2001), its real importance in laser welding has never been completely defined because of the occurrence of other processes such as the flow around the capillary due to the side-ways fluid flow resulting from the recoil pressure. We also have to mention the magnetohydrodynamic effects (Kern et al., 2000). Its importance has been clearly evidenced, when a current or/and a magnetic field is injected in the melt pool. Finally, there is also the flow induced by vapour friction due to the metal vapour ejected along the capillary. The effect of this mechanism, which has not often been quoted (Beck, 1996, Sudnik et al., 2000), has not really been observed experimentally. We will show in Section 8.3 why it has to be taken into account very seriously and that its importance is essential. 


\subsection{Keyhole formation and dynamics}

\subsubsection{Front keyhole wall behaviour}

The recoil pressure induced by the evaporation process occurring at the surface of a melt pool created by a laser beam impinging a metallic surface is the main mechanism of keyhole generation. This effect, similar to the drilling process, but at much lower intensity, has been clearly described by Semak and Matsunawa (1997). For static conditions, i.e., without relative displacement between the laser and the sample, it is a 'piston model': the recoil pressure deforms the liquid surface, the liquid being pushed sidewards and then deeper penetration of the vapour/liquid interface is allowed. A simple 1D semi-analytical model, where the basic conservative laws are applied to the liquid volume, can thus be used in order to determine a 'drilling velocity' $\mathrm{V}_{\mathrm{d}}$, which corresponds to the velocity of propagation of the liquid interface inside the solid (Fig. 8.1(a)): The incoming flow of material due to the velocity $V_{d}$ is lost by lateral ejection of the melt with a velocity $V_{m}$ and by evaporation at the vapour/liquid interface; The absorbed intensity is lost through thermal conduction inside solid, through melt generation at the solid/liquid interface, through convection due to lateral melt ejection at $\mathrm{V}_{\mathrm{m}}$, and finally through evaporation at the vapour/liquid surface. For these stationary conditions, the drilling speed and the surface temperature controls the thickness of the melt volume; Finally, the lateral melt ejection at $\mathrm{V}_{\mathrm{m}}$ results in the applied pressure (Bernoulli effect) due to surface evaporation characterized by a surface temperature, $\mathrm{T}_{\mathrm{s}}$, that defines the evaporation rate and the applied pressure by using Hertz's evaporation theory and local vapour saturation pressure dependence.

One of the main results of this piston model is that for typical absorbed intensities less than about $10 \mathrm{MW} / \mathrm{cm}^{2}$, characteristic of present lasers, the

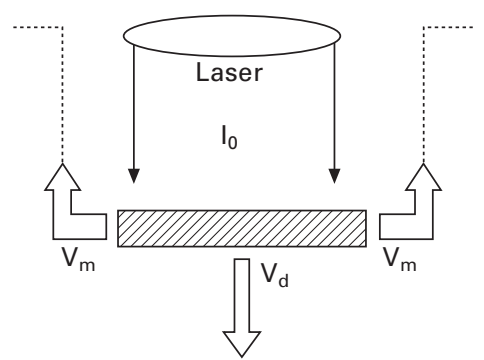

(a)

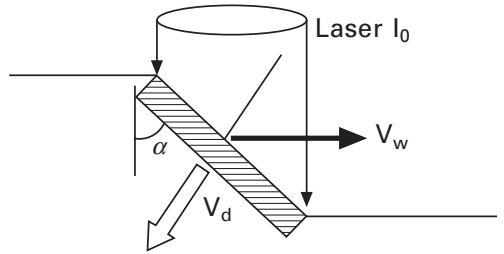

(b)

8.1 (a) Scheme of the 'piston model' related to the propagation of the liquid volume inside solid, for static conditions. The laser irradiates the surface with a focal spot of diameter D. (b) Inclination of the keyhole front wall during welding with the welding speed $\mathrm{V}_{\mathrm{w}}$. 
main mechanism of energy consumption is convection through lateral melt flow ejection where the melt flow can reach rather high velocities, typically $10 \mathrm{~m} / \mathrm{s}$, which are one order of magnitude greater than the corresponding drilling velocities $\mathrm{V}_{\mathrm{d}}$. Also in that range, one typically observes a quite linear dependency of drilling velocity with absorbed intensity $\mathrm{I}_{\mathrm{abs}}: \mathrm{V}_{\mathrm{d}}=\mathrm{k} \cdot \mathrm{I}_{\mathrm{abs}}$, (with $\mathrm{k} \approx 310^{-11} \mathrm{~m}^{3} \mathrm{~J}^{-1}$ ). For higher absorbed intensities, the drilling velocity still increases but the absorbed intensity is mainly used for evaporation of material at the liquid surface.

Now if one takes into account the relative displacement of the laser beam with the sample at a welding speed $\mathrm{V}_{\mathrm{w}}$, the stationary position of the resulting front will depend of the combination of this welding speed $V_{w}$ and the drilling one $V_{d}$ (Fig. 8.1(b)). Due to the finite transit time of a surface element under the laser beam, this front will be inclined and its inclination, $\alpha$, relatively to the vertical, can be determined by considering that this front has to be stationary in the laser beam frame (Fabbro and Chouf, 2000a, 2000b, Fabbro et al., 2005). A basic condition for this equilibrium condition states that the projection of the welding speed $\mathrm{V}_{\mathrm{w}}$ along the normal of this front has to be equal to the drilling speed $\mathrm{V}_{\mathrm{d}}$ (directed along this normal). This relation is then written as

$$
\mathrm{V}_{\mathrm{w}} \cdot \cos (\alpha)=\mathrm{V}_{\mathrm{d}}=\mathrm{kI}_{\mathrm{abs}}
$$

In eqn 8.1 we have used the previous result of the piston model about the relation of the drilling speed with the absorbed intensity $\mathrm{I}_{\mathrm{abs}}$. But the absorbed intensity depends of the incident intensity $\mathrm{I}_{0}$, and the surface absorptivity $\mathrm{A}(\alpha)$ with the incidence $(\pi / 2-\alpha)$, so

$$
\mathrm{I}_{\mathrm{abs}}=\mathrm{I}_{0} \cdot \mathrm{A}(\alpha) \cdot \sin \alpha
$$

For the sake of simplicity we will consider in the following that the absorptivity is rather constant with $\alpha$ : $\mathrm{A}(\alpha)=\mathrm{A}_{0}$ (measurements of $\mathrm{A}$ for these conditions (Fabbro et al., 2005) have shown that the surface absorptivity of the front keyhole wall is rather high typically 60 to $70 \%$; moreover, as this surface probably has many ripples, the incidence dependence has to be low (Bergström et al., 2007)).

Combination of eqns 8.1 and 8.2 gives the fundamental relation:

$$
\operatorname{tg}(\alpha)=\mathrm{V}_{\mathrm{w}} /\left(\mathrm{k} \mathrm{I}_{0} \mathrm{~A}_{0}\right)
$$

As can be physically expected, eqn 8.3 shows that the inclination of the keyhole front increases with the welding speed or when the incident intensity decreases. A direct consequence of eqn 8.3 concerns a possible estimation of the penetration depth $\mathrm{L}$ obtained during welding, for some simplifying conditions where a constant incident intensity $\mathrm{I}_{0}$ inside a focal spot of diameter $\mathrm{D}$, and a rather large absorptivity, $\mathrm{A}_{0}$, in order to neglect 
multiple reflections are assumed (these simplifications could be justified when Nd:YAG incident laser power is delivered through a fibre and also because rather high measured absorptivities are considered (Fabbro et al., 2005)). From eqn 8.3 one easily obtains

$$
\mathrm{L}=\mathrm{D} / \operatorname{tg}(\alpha)=\mathrm{k} \mathrm{I}_{0} \mathrm{~A}_{0} \mathrm{D} / \mathrm{V}_{\mathrm{w}}=\left(4 \mathrm{~A}_{0} \mathrm{k} / \pi\right) \cdot \mathrm{P} /\left(\mathrm{D} \cdot \mathrm{V}_{\mathrm{w}}\right)
$$

where $\mathrm{P}$ is the incident laser power $\mathrm{P}$ (in $\mathrm{W}$ ).

It is interesting to note that this non-obvious linear scaling of the penetration depth, $\mathrm{L}$, with the ratio $\mathrm{P} / \mathrm{D}$ has been obtained experimentally during Nd:YAG laser welding experiments for similar conditions (Dausinger et al., 2002). The scaling law in $1 / \mathrm{V}_{\mathrm{w}}$, which is also verified experimentally, will be discussed later in this chapter. Of course, if the absorptivity of the keyhole front is not so important, the reflected beam may also contribute to the penetration depth, following the same previously described mechanism. This process is then repeated, and penetration will stop when the final reflected beam is directed horizontally or even its intensity becomes less than some characteristic threshold for local evaporation. For realistic absorptivities (about 50\%), it can be shown that the contribution of the first reflection given by eqn 8.4 to the penetration depth represents about $50-60 \%$ of the total penetration depth, which is achieved with about three reflections (Fabbro and Chouf, 2000a).

The previous model allows us to observe a rather surprising property of the keyhole front: At low welding speed, when the inclination angle $\alpha$ is small, one can see from eqns 8.2 and 8.3 that the absorbed intensity on the keyhole front is simply given by:

$$
\mathrm{I}_{\mathrm{abs}}=\mathrm{V}_{\mathrm{w}} / \mathrm{k}
$$

For example, for usual conditions such as $\mathrm{P}=4 \mathrm{~kW}, \mathrm{D}=0.6 \mathrm{~mm}, \mathrm{~A}_{0}=0.6$ and $\mathrm{V}_{\mathrm{w}}=2.5 \mathrm{~m} / \mathrm{min}$, one obtains $\alpha=10^{\circ}$ and $\mathrm{I}_{\mathrm{abs}}=0.14 \mathrm{MW} / \mathrm{cm}^{2}$, which is much less than the incident intensity $\mathrm{I}_{0}=1.4 \mathrm{MW} / \mathrm{cm}^{2}$. Eqn 8.5 shows that the absorbed intensity only depends on the welding speed and not on the incident intensity. This self-regulating mechanism shows that as the incident intensity $\mathrm{I}_{0}$ increases, the penetration depth also increases, but with a constant absorbed intensity due to the decrease of the front keyhole inclination. Of course, at very high welding speeds, as the inclination $\alpha$ increases, the absorbed intensity also increases and approaches $\mathrm{I}_{0} \cdot \mathrm{A}_{0}$.

\subsubsection{Rear keyhole wall behaviour}

The previous analysis only concerns the keyhole front where the 'piston model' has been applied on a keyhole front whose inclination is variable. As the focal spot is usually circular, the melt ejected laterally flows around it and then reaches the rear side of the focal spot where the melt pool is then 
generated. This rear keyhole wall surrounded by the melt pool is subjected to two pressures $\mathrm{P}_{\mathrm{s}}$ and $\mathrm{P}_{\mathrm{m}}$, which are acting for the keyhole closure. $\mathrm{P}_{\mathrm{s}}$ is the surface tension pressure $(=2 \sigma / \mathrm{D}, \sigma$ surface tension $)$ and $\mathrm{P}_{\mathrm{m}}(\approx 0,5$ $\rho_{\mathrm{m}} \mathrm{V}_{\mathrm{m}}^{2}, \rho_{\mathrm{m}}$ is the melt density) is the dynamic pressure induced by the melt flow around the keyhole at the speed $\mathrm{V}_{\mathrm{m}}$. Usually, unless using very high welding speeds, the surface tension pressure $\mathrm{P}_{\mathrm{s}}$ is much more important than the dynamic one. The closing speed $\mathrm{V}_{\mathrm{c}}$ during keyhole collapse observed when, for example, the laser is switched off, can be obtained by a Bernoullilike relation given by Kroos et al. (1993):

$$
\mathrm{V}_{\mathrm{c}} \approx\left(\left(\mathrm{P}_{\mathrm{s}}+\mathrm{P}_{\mathrm{m}}\right) / \rho_{\mathrm{m}}\right)^{1 / 2}
$$

Typically for $\mathrm{D}=0.6 \mathrm{~mm}$ in mild steel $(\sigma \approx 1.5 \mathrm{~N} / \mathrm{m}), \mathrm{V}_{\mathrm{c}} \approx 0.8 \mathrm{~m} / \mathrm{s}$, which is very rapid compared to melt velocity $\mathrm{V}_{\mathrm{m}}$. It is interesting to mention here that when the thickness of the sample, which is welded in full penetration, is smaller than 1.25D, the reverse curvature of the rear keyhole wall towards the melt pool due to the finite thickness is greater than the curvature corresponding to the spot diameter, an opposite effect to keyhole closure is observed: it opens the keyhole and so elongates it inside the melt pool (Aalderink et al., 2007).

In order to keep the keyhole opened, it is then necessary to balance these two closing pressures by an opening one, that would result from the local ablation pressure $\mathrm{P}_{\mathrm{a}}$ due to impinging laser beam (by direct irradiation from the incident beam or resulting from multiple reflections inside the keyhole) and/or from the dynamic pressure $\mathrm{P}_{\mathrm{d}}$ of ejected vapour plume from the keyhole front that collides with the rear keyhole front. Depending of the sign of the net pressure $\Delta \mathrm{P}=\left(\mathrm{P}_{\mathrm{a}}+\mathrm{P}_{\mathrm{d}}\right)-\left(\mathrm{P}_{\mathrm{s}}+\mathrm{P}_{\mathrm{m}}\right)$, which can be positive or negative, the resulting velocity $\mathrm{V}^{\prime}$ of the rear keyhole wall that will tend to open or close it respectively, can be estimated by analogy with the drag effect of a flow around an obstacle that follows (Fabbro and Chouf, 2000b):

$$
\Delta \mathrm{P} \approx 0.88 \rho_{\mathrm{m}} \mathrm{V}_{\mathrm{c}}^{\prime 2}
$$

One has also to notice that for similar recoil pressure, because one pushes a liquid volume instead of a liquid film flowing along the surface of a solid, the corresponding 'drilling' velocities on the rear keyhole wall are much more important than on the front one. We have only considered here the dynamic effect $\mathrm{P}_{\mathrm{d}}$ of the vapour plume ejected from the keyhole front that impinges the rear keyhole wall. We will show in the Section 8.3.1 that it has also an important drag effect, mainly operating at low welding speed, which is directed along the keyhole axis where the shear stress induced at the liquid surface of the rear keyhole wall generates an upwards flow of this part of the keyhole. 


\subsubsection{Keyhole dynamics}

The different previous mechanisms can then be used for describing the dynamics of the keyhole geometry in a very simple and efficient way by assuming some simplifications (Fabbro and Chouf, 2000b). As we are only interested in the front or rear keyhole walls behaviour, we will only consider a 2D geometry in the X-Z plane (Fig. 8.2). For a given keyhole geometry, at time $t$, one can therefore determine the complete distribution of absorbed laser intensity along the keyhole walls, using ray tracing by taking into account multiple reflections inside the keyhole and Fresnel absorptivity. The components of drilling or closing velocity can then be locally estimated by applying the piston model (Semak and Matsunawa, 1997) on the front keyhole wall or eqn 8.7 along the rear keyhole wall. By adding to these components the welding velocity $\mathrm{V}_{\mathrm{w}}$, the complete flow field of the keyhole surface is then determined and its spatial evolution can be followed after each time step. Some examples of results obtained by using this $2 \mathrm{D}$ model are shown here in order to point out the characteristic behaviour of keyhole dynamics.

Figure 8.3 shows an example of keyhole profile evolution for partial penetration when the laser is switched on (Fabbro and Chouf, 2000b): A quasi-stationary profile is reached after about 20 milliseconds. Maximum depths show characteristic fluctuations of about $1 \mathrm{~mm}$, on a time scale of 5-10 ms, which are typically seen experimentally. This spiking process results from 'humps' going downward along the quasi-stationary keyhole front and closing the keyhole at its bottom. These humps, initially localized at the top of the keyhole front, are triggered by laser reflections coming from the rear keyhole wall. The rear keyhole wall is very sensitive to the multi-reflection field inside the capillary; it therefore always fluctuates strongly and sometimes

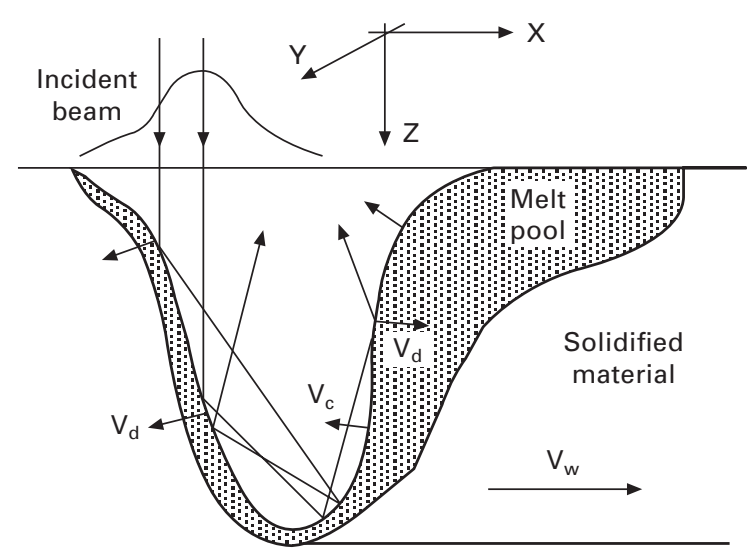

8.2 Keyhole geometry used in our 2D model. The profile is homogenous along the $\mathrm{Y}$ axis perpendicular to the welding direction (X axis). 

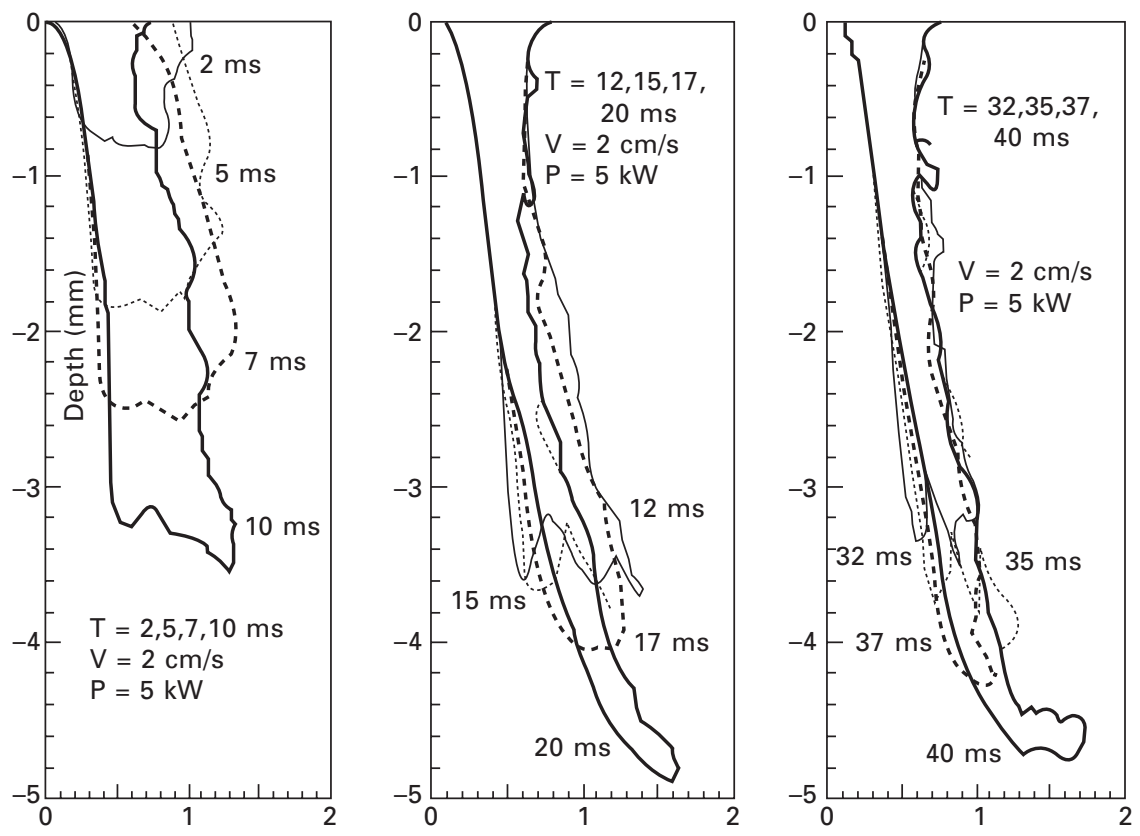

8.3 As a function of time (from 0 to $40 \mathrm{~ms}$ ), examples of the evolution of keyhole profiles along the welding direction (same frame as in Fig. 8.2). Beam parameters : $5 \mathrm{~kW}$ incident laser power, Gaussian distribution, $0.5 \mathrm{~mm}$ beam radius, iron sample, welding speed: $1.2 \mathrm{~m} / \mathrm{s}$. Peak incident intensity is located at the abscissa $X=$ $0.35 \mathrm{~mm}$. Maximum keyhole depth is reached after about $20 \mathrm{~ms}$.

shows highly local deformations that could initiate local porosities mainly located at the bottom of the keyhole, which can be trapped by the melt pool. X-ray experiments of Matsunawa et al. (1998), and Katayama et al. (2000) show very similar behaviour.

By using these simulations, the effect of the welding speed on typical keyhole profiles can easily be analyzed: As observed experimentally, its depth decreases and its mean inclination increases with the welding speed. At very high speed, one can see that the rear keyhole wall is strongly perturbed by the direct beam reflected from the front keyhole wall. Twin beam irradiation can also be simulated: the corresponding profile is then elongated, with its middle upper part being much more stabilized than with a mono-spot irradiation. This behaviour could be correlated to the improvement observed experimentally on the quality of the weld seams when twin beams are used (Hohenberger $e t$ al., 1999). In fact, this improvement also has to be considered from a better ability for metal vapour evacuation from the keyhole for these conditions (see Section 8.3.1).

Full penetration conditions can also be analyzed. Moreover, the impact of $\mathrm{Zn}$ vapour jet generated during overlap welding of $\mathrm{Zn}$-coated sheets can 
also be simulated and its effect on the rear keyhole wall compares favourably with corresponding experiments (Fabbro et al., 2006a).

\subsection{Melt pool dynamics}

We have previously seen that the keyhole geometry is very sensitive to several specific mechanisms and as it is embedded inside the melt pool, the keyhole coupling with the melt environment controls the hydrodynamics of this melt pool. Several techniques have been used for studying melt pool properties. The visualization, in the visible range, of its upper outside part apparently seems easy; also for 20 years, the use of X-ray radiography by Matsunawa and his colleagues has been a very powerful technique that allowed him to study the dynamics of keyhole geometry and also some aspects of the internal hydrodynamics of melt pool with adapted tracers (Katayama et al., 2000). However as these experiments suffer from rather limited spatial and also temporal resolution, only partial penetration conditions at relatively low welding speeds (or rather deep penetrations) have been analyzed. With the rather recent advent of sensitive high-speed video cameras, the analysis of the behaviour of the melt flow visible from the upper surface of the melt pool and its outside 3D geometry became much simplified, and moreover with very high temporal and spatial resolutions, particularly useful at high welding speeds. Finally, the combination of these two techniques in addition to other specifics experiments, has allowed real progress in the understanding of the complex hydrodynamics of the melt pool generated during laser welding.

As the melt pool characteristics and behaviour are primarily dependent on incident power and welding speed, one must analyze the melt pool characteristics on a rather wide range of these parameters. In order to discuss the main mechanisms involved in the hydrodynamics of the melt pool, we will describe a set of experiments mainly achieved during Nd:YAG laser welding, with incident power varying from 2.5 to $4 \mathrm{~kW}$, a top-hat beam of $0.6 \mathrm{~mm}$ diameter, on $304 \mathrm{~L}$ stainless steel for partial penetration conditions. Welding speed was varied from a few $\mathrm{m} / \mathrm{min}$ to $40 \mathrm{~m} / \mathrm{min}$. The main diagnostic was a high-speed visible video camera (up to $30 \mathrm{kHz}$ ) used for visualizing melt pool surfaces along different angles of view. By adapting the angle of view of the camera and its wavelength filtering, the plasma plume behaviour could also be recorded with a high contrast.

\subsubsection{Characteristic melt flow regimes}

For a given incident laser power, five different very characteristic melt flow regimes can be defined when the welding speed increases. Let us describe them first for an incident laser power of $4 \mathrm{~kW}$. 


\section{Welding speeds below $5 \mathrm{~m} / \mathrm{min}$ : 'Rosenthal' regime}

This regime, observed for welding speeds below $5 \mathrm{~m} / \mathrm{min}$ is characterized by a rather large melt pool, even in front of the keyhole, because of the rather low welding speed that favours heat conduction regime. It is characterized by important chaotic oscillations of the melt pool surface with large swellings of liquid fluctuating around the keyhole aperture, which remains here rather well defined and circular (see Fig. 8.4).

Because of these strong fluctuations, no clear flow around the keyhole can be observed, and many spatters are mainly emitted from the keyhole rim, particularly on its front side. Also, the vapour plume presents important fluctuations in its ejection that can be correlated with the previously described melt pool swelling fluctuations. Weld seam cross-sections show a gradual transition from the well-known 'wine cup shape' characteristic of these low welding speeds (typically about 1 to $3 \mathrm{~m} / \mathrm{min}$ ) to a more slender shape for 5 $\mathrm{m} / \mathrm{min}$. So, considering only thermal aspects, they result from a 'Rosenthal' heat flow regime (Carslaw and Jaeger, 1962) where a vertical cylindrical keyhole with its surface quite uniformly heated at a temperature close to the evaporation one, is surrounded by a large melt pool with no major flow.

For these low welding speeds, the penetration depth becomes important with negligible keyhole inclination. Consequently, these rather large aspect

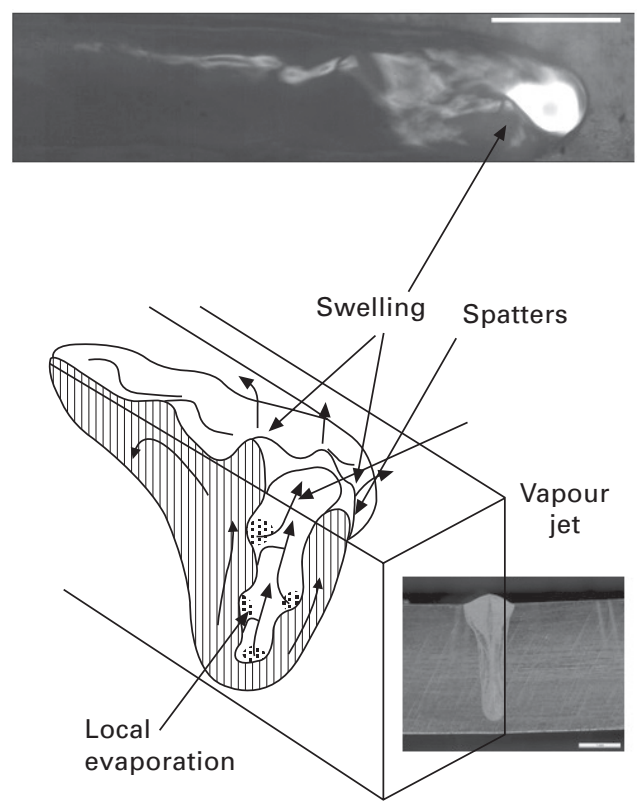

8.4 Sketch of the 'Rosenthal' regime, for welding speeds lower than $5 \mathrm{~m} / \mathrm{min}$. Typical view of melt pool (scale: $1 \mathrm{~mm}$ ) and cross-section (scale: $0.5 \mathrm{~mm}$ ). 
ratios (depth/diameter) will favour the appearance of Rayleigh instability (Tsukamoto et al., 2001) and friction effects induced by drag forces acting on the keyhole wall by the ejected vapour along the keyhole axis (Fabbro, 2002). Rayleigh instability results from possible closures along the keyhole axis, due to surface tension, when its length is 3 to 4 times greater than its diameter (Tsukamoto et al., 2001). This capillary instability is at the origin of porosity formation due to local keyhole closure, particularly at the bottom of the keyhole in the case of partial penetration, which generates bubbles in the molten pool that may be solidified later. Marangoni effect resulting from gradient of tension surface at the surface of the melt pool is often quoted as being responsible for the 'wine glass shape' observed for these welding conditions.

However, adapted experiments using combinations of twin or triple closed focal spots in static or at low welding speeds have shown show that resulting surface hydrodynamic flows are not compatible with the Marangoni effect (Fabbro et al., 2004) (see Fig. 8.5). The drag forces of the expanding metallic vapour accelerate a hydrodynamic flow along the keyhole walls that spreads along radial direction when the melt pool surface is reached. One can estimate that the shear stress $\tau_{\mathrm{g}}$ of the vapour ejected from the keyhole at a mean velocity $\mathrm{V}_{\mathrm{g}}$ is typically about $100 \mathrm{~N} / \mathrm{m}^{2}\left(\tau_{\mathrm{g}} \approx\right.$ $8 \eta_{\mathrm{g}} \mathrm{V}_{\mathrm{g}} / \mathrm{D}$, with $\eta_{\mathrm{g}}$ as the dynamic viscosity of vapour); it therefore induces by friction an upward melt flow velocity $\mathrm{U}_{0} \approx 4$ to $7 \mathrm{~m} / \mathrm{s}$ along the keyhole wall at its top part $\left(\mathrm{U}_{0} \approx 3\left(\tau_{\mathrm{g}} \mathrm{L} / \eta_{\mathrm{m}} \rho_{\mathrm{m}}\right)^{1 / 3}, \eta_{\mathrm{m}}\right.$ melt dynamic viscosity and $\mathrm{L}$ keyhole length). This velocity is very high, and it is similar to the melt flow velocity experimentally observed at the sample surface in Fig. 8.1. Therefore, this mechanism that increases with the deep keyhole and/or smaller spot diameter is very efficient for melt displacement. These estimations are underestimated if one considers that this previous process generally leads to Kelvin-Helmholtz surface instabilities. In that case, the inside keyhole surface can be highly perturbed, spatters may be accelerated by the vapour flow, and beam propagation inside the keyhole must also be perturbed. All these conditions are, of course, very favourable for triggering Rayleigh instability, and finally these mechanisms limit the penetration depth to a finite value for static conditions. From these considerations, one can also understand the improvement generally observed when using large keyhole sections such as those obtained with elongated focal spots (Hohenberger et al., 1999). Much less shear stress occurs inside these enlarged keyholes and so less liquid acceleration is induced, contributing to the improvement of weld seam quality. This behaviour is consistent with X-ray radiography experiments of Kinoshita et al. (2006) at low welding speeds where complex melt flow is observed near the keyhole inside the melt pool: a downwards directed flow was rather observed near the bottom of the keyhole and an upward directed one near the top of it. 


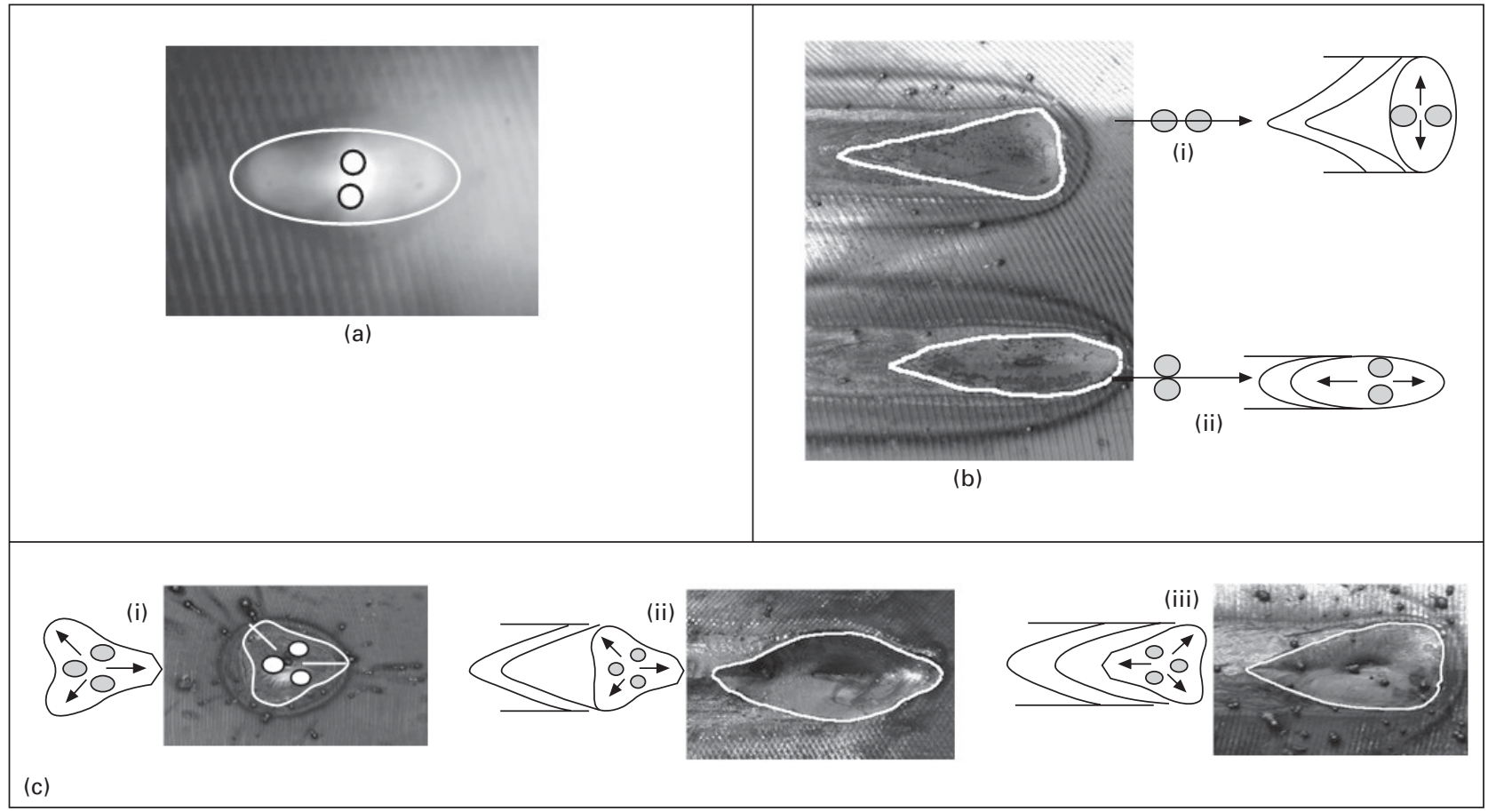

8.5 (a) Melt pool contour at the surface after $2 \mathrm{~s}$ of static irradiation using twin spots $(2 \times 4 \mathrm{~kW}$ Nd:Yag laser power, $0.6 \mathrm{~mm}$ focal spot diameter, $0.7 \mathrm{~mm}$ axial distance). The melt pool contour at the surface and the two keyholes have been visualized. (b) Melt pool contours at the sample surface during displacement, for longitudinal (i) and transverse (ii) configurations for a twin spot $(2 \times 4 \mathrm{~kW}$ laser power). The melt pool contours at the surface have been visualized. Arrows show the main hydrodynamic flow at the melt surface. (c) Surface melt pool contours during a $2 \mathrm{~s}$ static irradiation (i) and during a displacement, for transverse (ii) and longitudinal (iii) for a triple spot configuration. The melt pool contours at the surface have been visualized. 
Welding speeds between 6 and $8 \mathrm{~m} / \mathrm{min}$ : 'Single wave' regime

For welding speeds ranging from 6 to $8 \mathrm{~m} / \mathrm{min}$, rather large single swellings generated near the top of the rear keyhole wall are observed (see Fig. 8.6) where melt droplets are emitted. Periodic rearwards ejection of this large melt wave generates back and forth melt pool oscillations leading to closure of the keyhole. Vapour plume, emitted rather deep inside the keyhole, collides with the melt pool and triggers these oscillations. Because of this high welding speed, the keyhole front begins to be inclined and this vapour plume, emitted perpendicularly from the keyhole front surface, is then rather directed rearwards (Fabbro et al., 2005). The analysis of plume deflection variations has already confirmed this result (Fabbro et al., 2006b). The coupling between the plume and the melt pool is very efficient because the melt pool width is rather narrow due to the high welding speed. As the melt is then mainly accelerated rearwards, the weld seam cross-section shows quite parallel sides.

Contrary to the previous regime, where the luminosity characterizing the laser heated surface was more uniformly and randomly distributed around

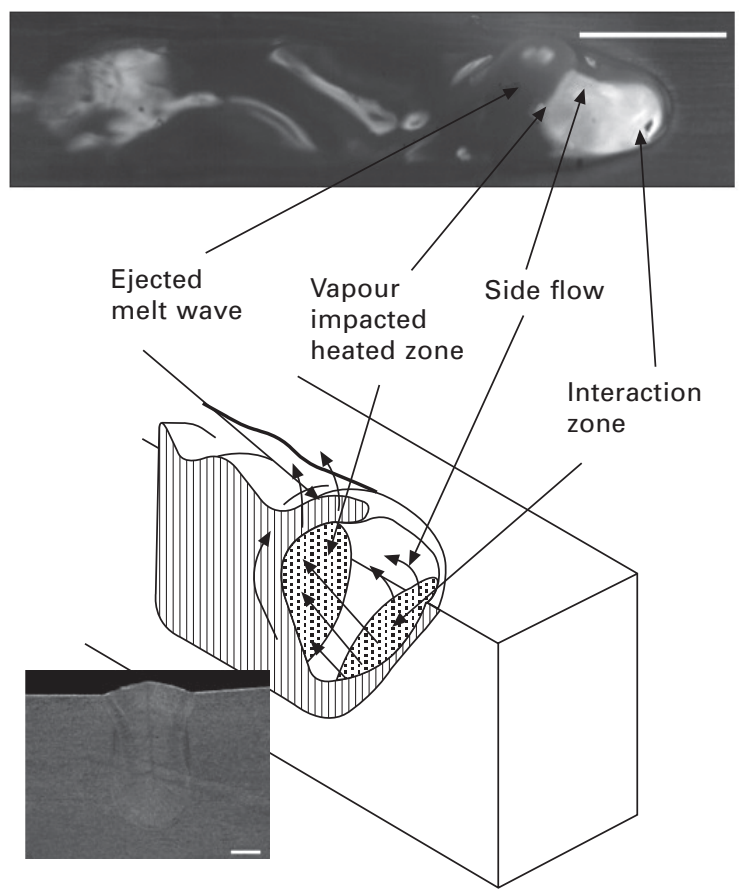

8.6 Sketch of the 'single-wave' regime, for welding speeds between 6 and $8 \mathrm{~m} / \mathrm{min}$. Typical view of melt pool (scale: $1 \mathrm{~mm}$ ) and crosssection (scale: $0.5 \mathrm{~mm}$ ) 
the keyhole surface, only the inclined keyhole front is clearly heated by the incident laser beam. Also, when the emitted vapour plume collides with the melt pool and lifts it, a corresponding local heating of the liquid surface by this energetic heated vapour plume can be observed. So the vapour plumes transfer not only impulse momentum but also energy probably due to the rather high temperature.

\section{Welding speeds between 9 and $11 \mathrm{~m} / \mathrm{min}$ : 'Elongated keyhole' regime}

An elongated keyhole is observed for welding speeds ranging from 9 to $11 \mathrm{~m} / \mathrm{min}$, with a maximum length of about $2 \mathrm{~mm}$, obtained at $11 \mathrm{~m} / \mathrm{min}$ (see Fig. 8.7). Although its length also presents some fluctuations, resulting liquid oscillations are much less intense than previously, and the height of the induced swellings is much smaller. This elongated keyhole shows two characteristic heated zones: the first one corresponds to the inclined keyhole front wall, similar to all regimes, and the second one is located at the rear end of this elongated keyhole, inside the melt pool. Moreover, a vapour plume also seems to be emitted from the second heated spot and so directed frontward. As in the previous regime, heating by the collision of the vapour

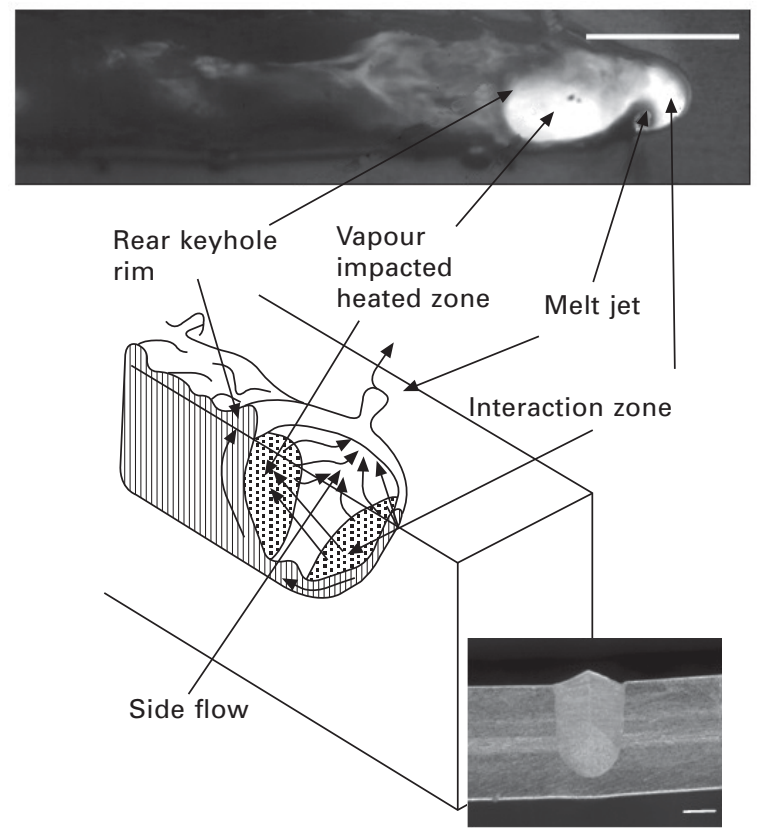

8.7 Sketch of the 'elongated' regime, for welding speeds between 9 and $11 \mathrm{~m} / \mathrm{min}$. Typical view of melt pool (scale: $1 \mathrm{~mm}$ ) and crosssection (scale: $0.5 \mathrm{~mm}$ ). 
plume emitted from the keyhole front is possible. But direct heating from some local reflection of the incident laser beam on some part of keyhole front cannot be excluded, even if the keyhole front reflectivity has been shown to be rather low (Fabbro et al., 2005).

Because this rear zone, surrounded by the melt pool, is rather efficiently heated, it produces a side melt flow that is directed frontward during a frontward melt pool oscillation. Consequently, this side flow collides with the usual equivalent side flow issued from the keyhole front near the centre of the elongated keyhole sidewall, and a resulting small jet directed upwards along the sidewalls is then formed. This jet is then quite periodically deposited on the sides at the sample surface and produces characteristic defects of the weld seam after solidification.

\section{Welding speeds between 12 and $19 \mathrm{~m} / \mathrm{min}$ : 'Pre-humping' regime}

For welding speeds ranging from 12 to $19 \mathrm{~m} / \mathrm{min}$, the melt flow contours the inclined keyhole front wall. This resulting 'keyhole' is then elongated (but with a shorter length than in the previous regime) and the surface of the resulting melt pool shows fluctuations characterized by only surface waves with rather small amplitudes.

The keyhole front is very stable, with increased inclination. The main melt flow is emerging from the bottom of the keyhole front wall and is deflected rearwards with the melt pool surface reaching a level close to the initial sample surface (see Fig. 8.8). So the concavity of the melt pool surface of this emerging flow is directed rearwards. No more spatters or droplets are emitted, even from the rear rim of the keyhole as in the previous regime. Above 15-16 $\mathrm{m} / \mathrm{min}$ welding speeds, some undercuts are observed on the sides of the seam. In that case, one can observe that the sides of this emerging melt do not rise up to the sample surface. Above $17-18 \mathrm{~m} / \mathrm{min}$, undercuts then begin to be important when the two side flows emitted from the keyhole front wall collide with the sides of the emerging flow and press the flow towards its centre. Finally, the vapour plume is very stable with no fluctuations and is precisely ejected perpendicularly from the keyhole front wall.

\section{Welding speeds above $20 \mathrm{~m} / \mathrm{min}$ : 'Humping' regime}

Above $20 \mathrm{~m} / \mathrm{min}$, we reach a very characteristic humping regime that is defined by the occurrence of a weld seam with very strong undercuts, composed of large solidified swellings of quite ellipsoidal shape, separated by smaller valleys (Fabbro et al., 2007b). As in the previous regime, the main flow is always emerging from the bottom of the keyhole front wall (see Fig. 8.9(a)); it is strongly deflected rearwards and its central part rises up to 


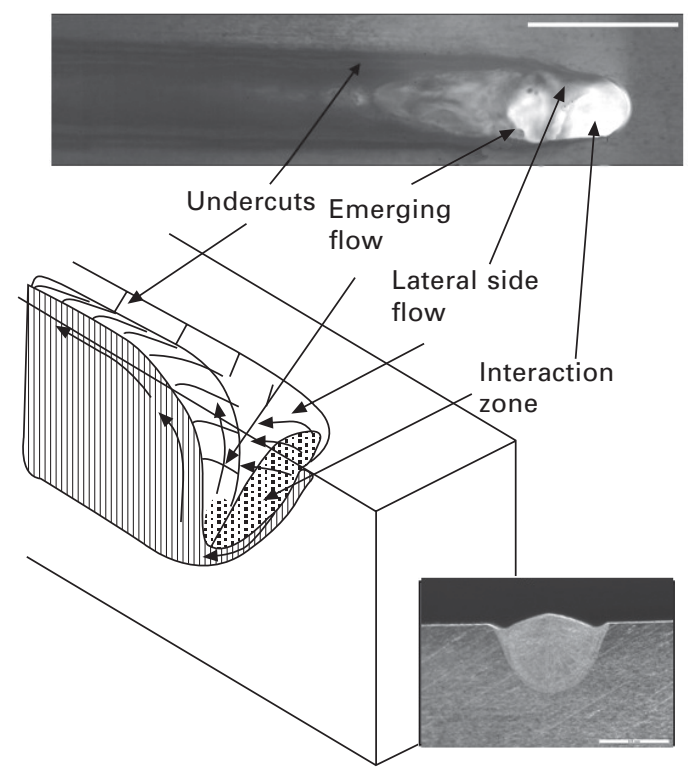

8.8 Sketch of the 'pre-humping' regime for welding speeds between 12 and $19 \mathrm{~m} / \mathrm{min}$. Typical view of melt pool (scale: $1 \mathrm{~mm}$ ) and crosssection (scale: $0.5 \mathrm{~mm}$ ).

a level now much lower than the surface sample. This flow stays attached to the sidewalls along a distance of about $2 \mathrm{~mm}$ and then the central part of this flow is detached and forms a thin vertical strip of liquid jet that propagates rearwards at high velocity. It is along this strip of liquid jet that the humps are generated. At a certain distance from the detachment point, typically $2 \mathrm{~mm}$, shrinkage of this strip melt jet due to the Rayleigh instability driven by surface tension appears. The local cooling of this jet at this shrinkage point stops the fluid flow and a hump can then grow. The growth of this hump is stopped when a new shrinkage occurs at a similar distance from the detachment point that provokes the growth of a new hump. Because this thin melt strip is located at the centre the groove, very severe undercuts are generated even around the humps (Fig. 8.9(b)). For higher welding speeds this scheme is not modified: the penetration depth slightly decreases, the emerging melt flow from the bottom of keyhole front wall is more deflected rearwards and the distance between humps slightly decreases.

\subsubsection{Regime partitioning in the $\left(P-V_{w}\right)$ plane}

These experiments have been reproduced by using incident laser powers varying between 2.5 and $4 \mathrm{~kW}$ (in order to have a greater range of incident intensities, focal spot was reduced to $0.45 \mathrm{~mm}$ ). These five regimes were 


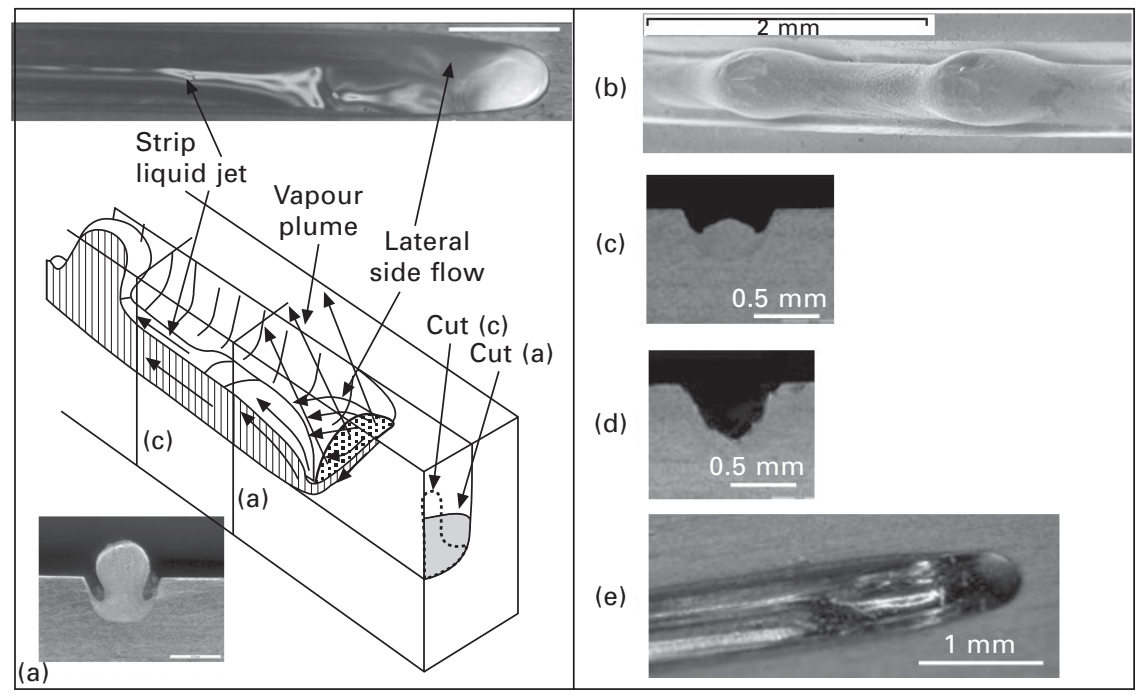

8.9 (a) Sketch of the 'humping' regime (for welding speeds greater than $20 \mathrm{~m} / \mathrm{min}$ ). Typical view of melt pool (scale: $1 \mathrm{~mm}$ ) and crosssection of a hump (scale: $0.5 \mathrm{~mm}$ ), (b) Example of a weld seam with characteristic humps (welding speed: $20 \mathrm{~m} / \mathrm{min}, \mathrm{P}_{\text {laser }}: 4 \mathrm{~kW}$ ) (c) Cross-section at position ' $c$ ' (surface $S_{c}$ can be defined from melted zone), (d) Cross-section at a position near the bottom of the keyhole front (surface $S_{\text {in }}$ can be defined there), (e) View of the keyhole front observed after laser switching off.

observed, but with modified welding speeds thresholds. Figure 8.10 shows these results where we have first delimited the regions where the welding is realized with a keyhole regime (labelled KR), and where only conduction regime is observed (labelled CR). Typically, for a welding speed of 25 $\mathrm{m} / \mathrm{min}$, keyhole regime is obtained for incident laser power greater than $0.5 \mathrm{~kW}$. Of course, this power increases with the welding speed. For incident power varying from 2.5 to $4 \mathrm{~kW}$, the welding speeds thresholds between the Rosenthal/Single-wave/Elongated/Pre-humping/Humping regimes have been reported (the five corresponding regimes are labelled respectively R, S, E, $\mathrm{P}, \mathrm{H})$. Except for the $\mathrm{P} / \mathrm{H}$ transition, the characteristic thresholds increase with the incident laser power. Best-linear fits passing through the origin can be plotted through these three series of experimental points for these consecutive regimes and will be discussed in Section 8.4.1.

For the $\mathrm{P} / \mathrm{H}$ transition, for incident laser powers smaller than $2.5 \mathrm{~kW}$, no humping instability can be observed, even at very high welding speed. Also, when the incident power increases, the $\mathrm{P} / \mathrm{H}$ welding speed threshold decreases; this behaviour is similar to previous experimental results but obtained for different conditions (Thomy et al., 2006). This different behaviour of this $\mathrm{P} / \mathrm{H}$ transition compared to the three previous ones, probably results 


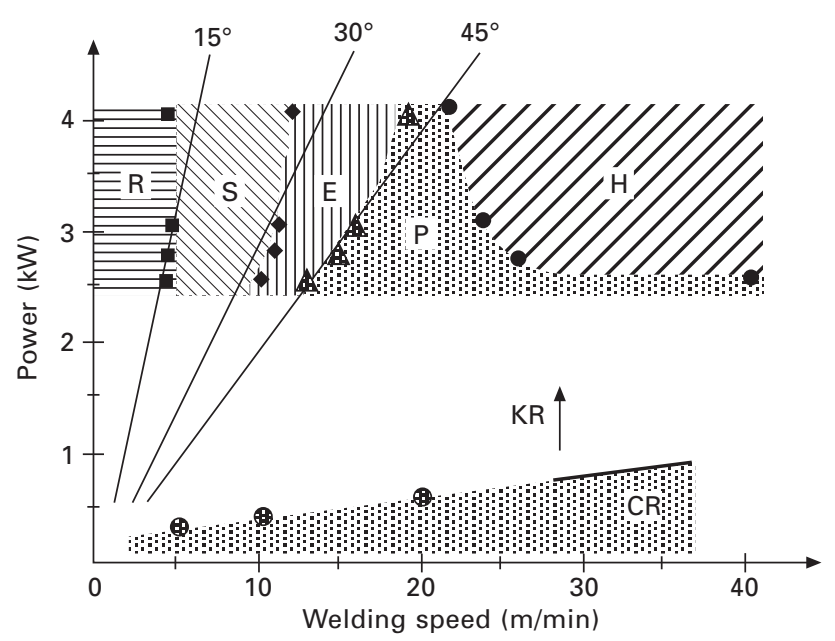

8.10 Location of the five previously described regimes respectively labelled $\mathrm{R}, \mathrm{S}, \mathrm{E}, \mathrm{P}, \mathrm{H}$, in the incident laser power-welding speed plane. Locations of keyhole $(\mathrm{K})$ and conduction $(\mathrm{C})$ regimes are also indicated. Linear best fits for the R/S, S/E and E/P transitions, with corresponding keyhole front wall inclination angle (focal spot diameter used here is $0.45 \mathrm{~mm}$ ).

from the very different mechanisms driving this humping instability. It is also interesting to notice that if we extrapolate the $\mathrm{P} / \mathrm{H}$ transition at higher incident powers, the pre-humping region should disappear. This behaviour could be verified by using higher laser powers, for example with new fibre or disc lasers.

\subsubsection{Additional observations}

Before tempting a global interpretation of the previous observation, one needs to discuss complementary results on that range of variation of welding speed. They concern the penetration depth of the keyhole, the determination of the front keyhole wall inclination and finally the estimation of the dynamic pressure of the ejected vapour plume with incident intensity.

\section{Penetration depth of keyhole}

A well-known behaviour of the effect of increasing welding speed concerns the decrease of penetration depth, L. This is shown on Fig. 8.11 for the previous experimental parameters. Also plotted on Fig. 8.11, the 1/L variation with the welding speed and a linear scaling fits correctly these experimental points for welding speeds greater than about $6-7 \mathrm{~m} / \mathrm{min}$. This scaling, usually verified for many experiments at rather high welding speeds, is coherent with 


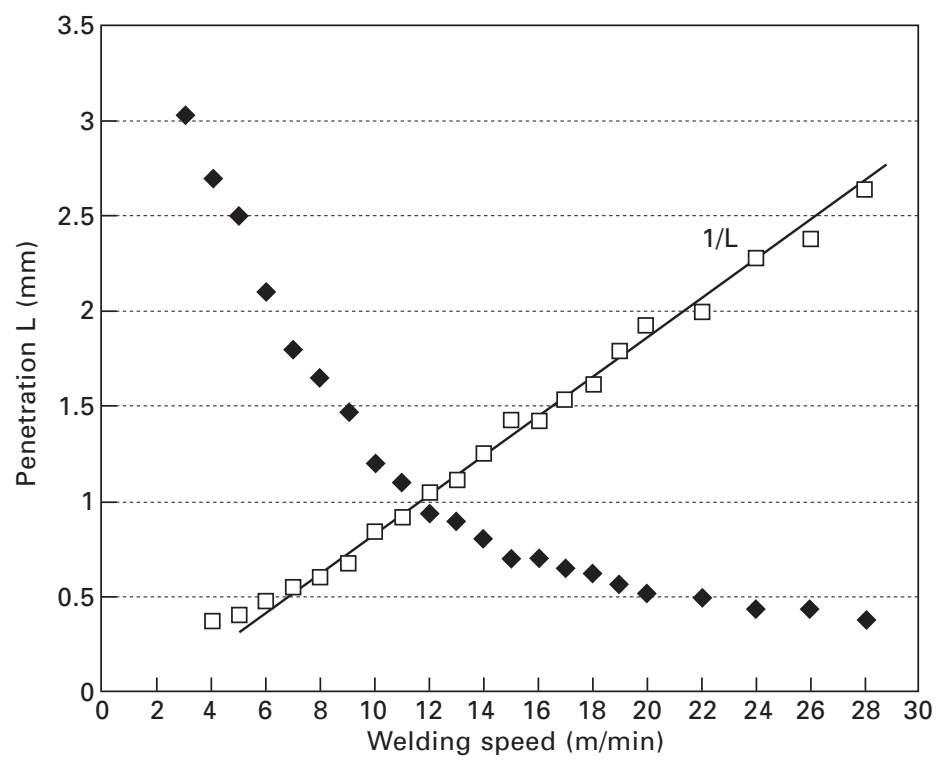

8.11 Penetration depths $L$ as a function of welding speed (incident power, $4 \mathrm{~kW}, 0.6 \mathrm{~mm}$ focal spot diameter, 304L stainless steel). Scaling of $\mathrm{L}^{-1}$ has also been reported.

the dynamic model previously described in Section 8.2.1 that explains the penetration depth dependence with the inverse of the welding speed. For welding speeds lower than $6-7 \mathrm{~m} / \mathrm{min}$, this scaling law is not satisfactory; penetration depths $L$ appear to be smaller, indicating some perturbing processes for beam propagation. Stochastic interruptions of beam propagation inside the keyhole by some melt movements due to the previously discussed keyhole instabilities are responsible of this behaviour.

\section{Front keyhole wall inclination}

The increase of the front keyhole wall inclination with the welding speed results in a decrease in penetration depth. This inclination could be directly observed on video movies during previous experiments or by analysis of the plume dynamics emitted from the keyhole. Very important fluctuations of the plume deviation (compared to the vertical laser axis) can be visualized by using the high-speed video camera located on the side, perpendicularly to the welding speed. These movies show that these plume fluctuations result from the back and forth melt pool movements that deflect the plume during its emission from the keyhole aperture, and their mean deviation is always directed towards the melt pool. On a given video sequence, maximum plume deviation always corresponds to minimum perturbation by the melt pool 
and therefore gives some information on the keyhole front wall inclination, because the evaporation process initially emits the vapour perpendicularly to the irradiated surface. Examples of corresponding images of plume ejection for various welding speeds are shown in Fig. 8.12(a) as the welding speed increases, maximum plume deviation decreases and the corresponding plume luminosity increases. Plume luminosity is related to the absorbed
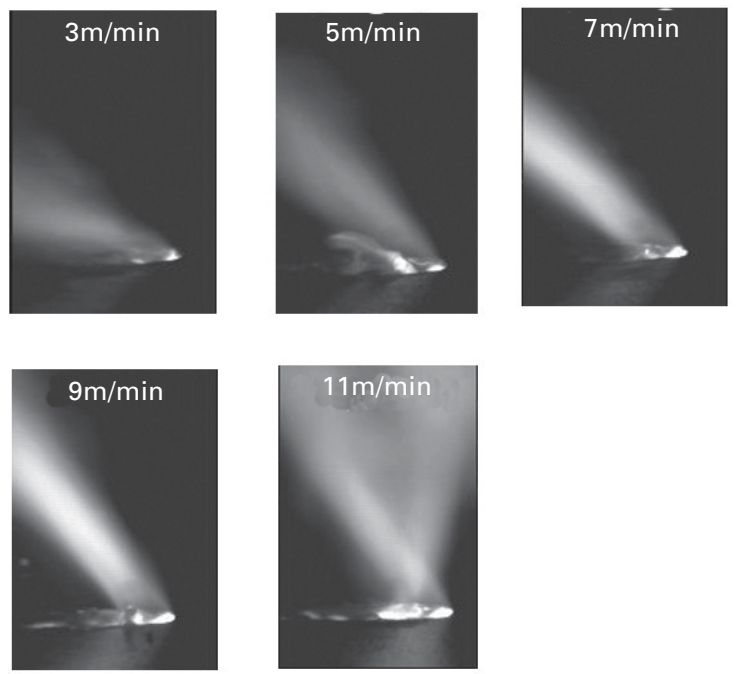

(a)

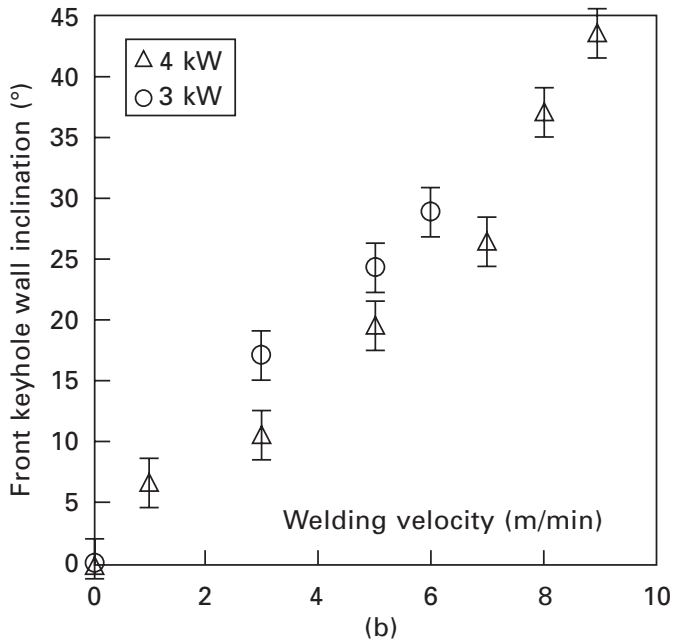

8.12 (a) Maximum plume deviation observed during a video sequence for different welding speeds. (b) Front keyhole wall inclination variation with welding speed for two incident laser powers. 
laser intensity: as front keyhole wall inclination increases, the absorbed intensity also increases (see eqn 8.2). So, the evaporation process becomes more intense with higher plume temperature or luminosity. Plume dynamic pressure is also expected to be more important (see Section 8.4).

The front keyhole wall inclination has also been measured by coaxial visualization through the focusing optics of the extension of the heated front keyhole wall when using samples of finite thickness, during full penetration experiments (Fabbro et al., 2005). Examples of front keyhole wall inclination variation with welding speed for different incident laser powers are shown in Fig. 8.12(b). The resulting scaling is also consistent with our dynamic model.

\section{Analysis of dynamic pressure of the ejected vapour plume}

The strong correlation observed between plume ejection and melt pool dynamics would be clarified if the dynamic pressure of the plume expansion is estimated. For pure 1D plume expansion, this dynamic pressure would also correspond to the recoil pressure applied at the keyhole front wall, as a result of the evaporation process, which drives the sideways melt ejection in the piston model. As these data had never been obtained for these experimental conditions, because of the very low level of involved pressures, which are applied on a rather small diameter in a complex geometry, an original technique based on the induced deflection of the vapour plume by using a side gas jet with a known momentum has been developed (Fabbro et al., 2006c). This technique consists in irradiating a sample in static conditions, with a rather short laser pulse (about few ms, in order to avoid a deep keyhole). The vapour plume emitted perpendicularly from the surface is then deflected by a transverse gas jet of argon with a known momentum (by knowing the flow rate from this nozzle). Assuming a mechanical collision between these two flows where total impulse momentum is conserved, the measurement of the deflection angle of vapour plume allows the determination of its initial vapour plume impulse momentum $\mathrm{P}_{\mathrm{d}}=\rho_{\mathrm{g}} \mathrm{V}_{\mathrm{g}}^{2}$. Figure 8.13 shows the data for three different materials: aluminium, iron and carbon-composite material. Linear best fits have been drawn and a very strong dependency of this dynamic pressure with the sample material can be observed. This evolution can be understood by using a crude ablation model, where the evaporation pressure $\mathrm{P}_{\text {evap }}$ is given by

$$
\mathrm{P}_{\text {evap }}=\mathrm{m}^{\prime} \mathrm{V}_{\mathrm{g}} \approx\left(\mathrm{I}_{\text {evap }} / \mathrm{L}_{\mathrm{v}}\right) \cdot\left(\mathrm{RT}_{\mathrm{v}} / \mathrm{A}\right)^{1 / 2}
$$

In eqn. $8.8, \mathrm{~m}^{\prime} \approx \mathrm{I}_{\mathrm{evap}} / \mathrm{L}_{\mathrm{v}}$ is the mass ablation rate of the material characterized by its enthalpy of vaporization $\mathrm{L}_{\mathrm{v}}$, and the intensity $\mathrm{I}_{\text {evap }}$ used for this ablation; $\mathrm{V}_{\mathrm{g}}$ is a characteristic plume expansion velocity approximated by the plume sound of speed $\left(\approx\left(\mathrm{RT}_{\mathrm{v}} / \mathrm{A}\right)^{1 / 2}\right)$ at evaporation temperature $\mathrm{T}_{\mathrm{v}}$ ( R 


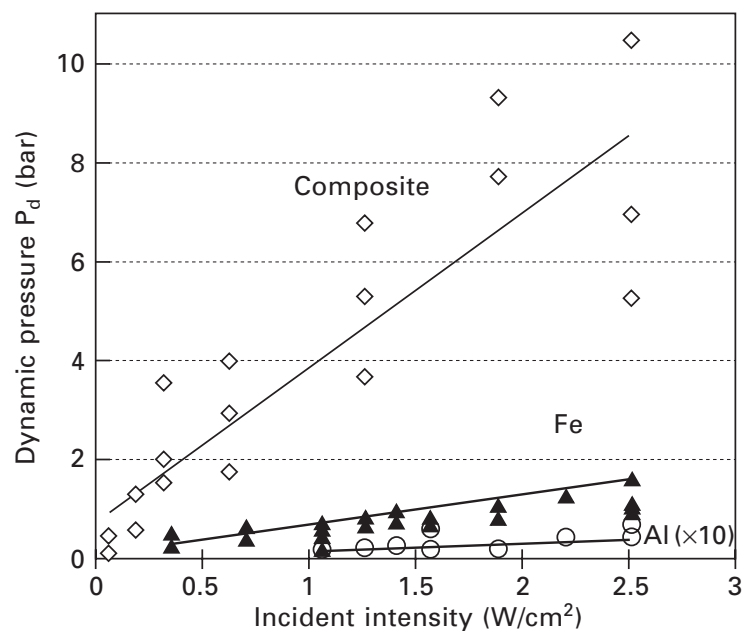

8.13 Variation of the dynamic pressure $P_{d}$ of the vapour plume as a function of incident laser intensity for three different sample materials (spot diameter: $0.45 \mathrm{~mm}$ ). For better visualization, aluminium data have been multiplied by a factor of 10 .

and A: gas perfect constant and atomic mass of vapour plume). Moreover, the evaporation intensity $I_{\text {evap }}$ is the difference between absorbed intensity $\mathrm{I}_{0} \cdot \mathrm{A}_{0}$ and the intensity lost by conduction $\mathrm{I}_{\text {cond }}$ inside material, so: $\mathrm{I}_{\text {evap }}=$ $\mathrm{I}_{0} \cdot \mathrm{A}_{0}-\mathrm{I}_{\text {cond }}$. Because of corresponding greater absorptivity $\mathrm{A}_{0}$ and lower conductivity losses $\mathrm{I}_{\text {cond }}$, when one considers successively aluminium, iron and composite material, the evaporation intensity increases and consequently the evaporation pressure $\mathrm{P}_{\text {evap }}$ given by eqn 8.8 .

So, for an incident intensity of about $1.4 \mathrm{MW} / \mathrm{cm}^{2}$ (corresponding to 4 $\mathrm{kW}$ incident laser power on a $0.6 \mathrm{~mm}$ focal spot diameter), which irradiates an iron sample, the induced dynamic pressure $P_{d}$ is typically 1 bar $\left(10^{5}\right.$ $\mathrm{Pa}$ ). But during laser welding, as the keyhole front wall is inclined, with an inclination depending of welding speed and incident intensity, the local intensity is then much lower. By using the previous experimental results concerning front inclination for determining the incident intensity on inclined keyhole front wall and data of Fig. 8.12, one can estimate the maximum dynamic pressure $P_{d}$ characteristic of the five regimes described in Section 8.3. For a $4 \mathrm{~kW}$ incident laser power and a $0.6 \mathrm{~mm}$ focal spot diameter, one typically finds:

Humping regime

Pre-humping regime

Elongated regime

Single-wave regime

'Rosenthal' regime
$\left(\mathrm{V}_{\mathrm{w}}>20 \mathrm{~m} / \mathrm{min}\right)$ :

$\left(12<\mathrm{V}_{\mathrm{w}}<19 \mathrm{~m} / \mathrm{min}\right)$ :

$\left(9<\mathrm{V}_{\mathrm{w}}<11 \mathrm{~m} / \mathrm{min}\right)$ :

$\left(6<\mathrm{V}_{\mathrm{w}}<8 \mathrm{~m} / \mathrm{min}\right)$ :

$\left(\mathrm{V}_{\mathrm{w}}<5 \mathrm{~m} / \mathrm{min}\right)$ :
$\mathrm{P}_{\mathrm{d}}>20 \mathrm{kPa}$

$\mathrm{P}_{\mathrm{d}}<20 \mathrm{kPa}$

$\mathrm{P}_{\mathrm{d}}<12-15 \mathrm{kPa}$

$\mathrm{P}_{\mathrm{d}}<\approx 10 \mathrm{kPa}$

$\mathrm{P}_{\mathrm{d}}<5-8 \mathrm{kPa}$ 
These data can be compared with the closing pressure due to surface tension of a $0.6 \mathrm{~mm}$ diameter keyhole that approaches about $5 \mathrm{kPa}$ $(\sigma \approx 1.5 \mathrm{~N} / \mathrm{m}$ for iron). Dynamic pressures obtained for rather high welding speeds are therefore sufficient for enlarging the keyhole as it is experimentally observed. This is no more the case at low welding speeds: we have seen that the absorbed intensity is then proportional to the welding speed (eqn. 8.5); consequently the evaporation pressure also decreases and may become smaller than the closing pressure due to surface tension. This is a possible mechanism of the non-stationary behaviour of the dynamics of the keyhole that is observed in the Rosenthal regime. From the obtained scaling laws, this process occurs on a range of welding speeds that increases when the focal spot diameter decreases.

\subsection{Discussion}

\subsubsection{Rosenthal, single-wave and elongated regimes: melt pool/plume coupling dominated regimes}

These results show the extreme importance of the direction and the dynamic pressure of the vapour plume for controlling melt dynamics. It must be recalled that the corresponding evaporation pressure is responsible for the 'piston effect' that 'drills' the keyhole by lateral melt ejection underneath the front keyhole wall. The generated vapour plume has a dynamic pressure that is very close to this evaporation pressure if its lateral expansion is limited, i.e. if the distance between the evaporation and rear keyhole walls is limited. This vapour can easily deform the rear keyhole wall. It also contains a certain amount of energy, which is not a negligible fraction of absorbed laser power used for the evaporation process (Semak and Matsunawa, 1997), which is thus transferred to the impacted surface.

These first three regimes (Rosenthal, single-wave and elongated) are dominated by the coupling of the vapour plume with the melt pool. As seen in Section 8.3.1, at low welding speeds ('Rosenthal' regime) the keyhole is quite vertical and fluctuates in shape, the absorbed intensity is then randomly distributed around its surface. Therefore, there are no preferential directions of vapour plume emission from the keyhole walls. The resulting mean upwards vapour flow is mainly directed along the keyhole axis and induces by friction effects along these thick liquid walls, a Kelvin-Helmholtz instability that generates the observed fluctuations and liquid swellings at the surface melt pool. The direction of the ejected vapour plume outside the keyhole follows the keyhole top shape during these fluctuations.

The keyhole front inclination increases with the welding speed. The main zone of evaporation is located near the bottom of the keyhole, an intense jet of vapour is locally generated and directed slightly rearwards. Its collision 
with the melt pool lifts this part of the melt pool and generates a strong rearward wave that induces a back and forth bouncing of the melt pool whose width becomes narrow due to the increased welding speed. The direction of the ejected vapour plume is then easily modified by this melt wave that gains a rearward momentum during the vapour plume-melt collision. This corresponds to the 'single wave' regime.

For higher welding speeds the keyhole front wall is more inclined and the evaporation zone is displaced towards the top along the keyhole front. The ejected vapour plume intercepts the top part of the melt pool along the keyhole rear wall and so the keyhole aperture is elongated. The previous single melt wave cannot be generated, but reduced oscillations of the melt pool still occur.

When increasing the welding speed, we reach the 'pre-humping' regime dominated by hydrodynamic flow. As the keyhole front wall is inclined (to typically about $50^{\circ}$ ), the intensity impinging this surface is much higher than at lower welding speeds. Therefore, the evaporation process becomes important and the dynamic pressure is very high, confirming the enhanced luminosity of the vapour plume. This plume is not perturbed by the melt flow emerging from the bottom of the keyhole. One can also suppose that the vapour plume is so dense and dynamic that it could efficiently deflect and accelerate rearwards this emerging melt flow emitted in the same direction as the plume. Also, this rearward deflection of this main melt flow is probably assisted by the side melt flow ejected laterally underneath the keyhole front wall.

The analysis of the partitioning in the $\left(\mathrm{P}-\mathrm{V}_{\mathrm{w}}\right)$ plane shown in Fig. 8.10 confirms the common origin for the R/S, S/E and E/P transition thresholds. Equation (8.3) can be rewritten as: $\mathrm{P}=\mathrm{B} \cdot \mathrm{V}_{\mathrm{w}}$, where the slope $\mathrm{B}$ of the linear relation between incident laser power $\mathrm{P}$ with $\mathrm{V}_{\mathrm{w}}$, is given by: $\mathrm{B}=$ $\left(\pi \mathrm{D}^{2} /\left(4 \mathrm{k} \mathrm{A}_{0} \operatorname{tg} \alpha\right)\right)$. The inclination angle $\alpha$ that reproduces the slopes of the three best-fit lines drawn on Fig. 8.10 are $15^{\circ}, 30^{\circ}$ and $45^{\circ}$ for respectively the $\mathrm{R} / \mathrm{S}, \mathrm{S} / \mathrm{E}$ and $\mathrm{E} / \mathrm{P}$ transitions. It is therefore very interesting to note that the evolution of these inclination angles is in fair agreement with the corresponding experimental observations. Our previous model also shows that this slope B is proportional to the penetration depth. Therefore, for a given transition $(\mathrm{R} / \mathrm{S}$, or $\mathrm{S} / \mathrm{E}$, or $\mathrm{E} / \mathrm{P})$ the different welding speed thresholds corresponding to that transition occur at the same penetration depth and inclination angle. As can be expected, corresponding penetration depths decrease as the welding speeds increase, i.e., when one goes from $\mathrm{R}$ to $\mathrm{P}$ regimes.

So these results would indicate that the transition between these first four regimes is basically controlled by a characteristic inclination angle of the keyhole front wall. As this inclination angle also defines the direction and the dynamic pressure of the emitted vapour plume, these results confirm that 
it is the level of interaction of the vapour plume with the rear melt pool that defines its hydrodynamic regime (Fabbro et al., 2007a).

It is interesting to note here that the observed flows in these pre-humping regimes are very similar to those generated when adequate Argon flow is precisely injected inside the keyhole (Kamikuki et al., 2002, Fabbro et al., 2006b). Resulting dynamic pressure and induced surface friction stresses of this Argon flow efficiently elongates the keyhole and properly directs a high-speed laminar melt flow rearwards similar to the pre-humping regime. In that case, it has been shown that improved penetration and weld seam quality are obtained. Figure 8.14 shows the scheme of the used experimental set-up and examples of melt pool with and without the side-gas jet. Moreover, the dynamic pressure of this Argon jet at the keyhole location (measured by using a Pitot tube manometer), for conditions leading to this controlled hydrodynamics of the melt pool, is about $15 \mathrm{kPa}$, and corresponds precisely to the dynamic pressure of the vapour plume for E/P transition. This agreement between pressures necessary for achieving similar effects on melt pool hydrodynamics, confirms the experimental determination of dynamic pressure measurements described in Section 8.3.3.

For the pre-humping regime, rearwards melt flow velocity is rather high, the melt pool is then elongated and no oscillations bouncing the melt back and forth are possible. So, contrary to the three previous regimes, the characteristic 'chevron' structure is no longer observed for pre-humping regime.

\subsubsection{Analysis of the humping regime: hydrodynamics dominated regime}

For welding speeds above the critical speed of $20 \mathrm{~m} / \mathrm{min}$ (for $4 \mathrm{~kW}$ incident laser power and $0.6 \mathrm{~mm}$ focal spot diameter) humping instability is triggered.

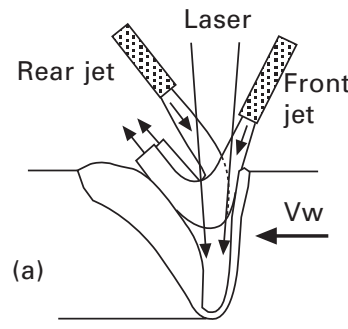

(b)

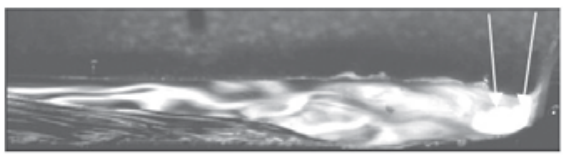

(c)

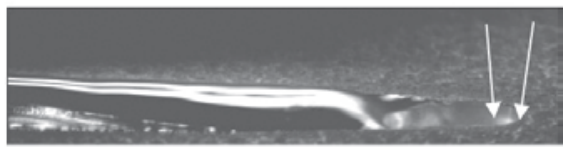

8.14 (a) Scheme of the side gas jet locations. The front and rear jet positions are shown and the flows exiting the nozzle are very simplified. (Nozzle diameter: $2 \mathrm{~mm}$ located at $5 \mathrm{~mm}$ from the keyhole; flow rate: $201 / \mathrm{min}$ Ar.) Melt pool images extracted from a video sequence obtained without (b) and with (c) a side gas jet. Welding speed: $3 \mathrm{~m} / \mathrm{min}$. $P_{\text {laser }}: 3 \mathrm{~kW}$. The white arrows visualize the incoming laser beam. 
There are no major modifications of the behaviour of the vapour plume ejected from the keyhole front wall compared to the 'pre-humping' regime. No interaction of this vapour plume occurs with the emerging melt flow at the keyhole bottom. As the absorbed intensity, and corresponding evaporation pressure, increase with welding speed, the melt flow accelerated by this rather large evaporation pressure reaches high velocities: as evaporation pressures for the humping regime are greater than $20 \mathrm{kPa}$, corresponding initial ejected melt velocities estimated from Bernoulli's relation are about $120 \mathrm{~m} / \mathrm{min}$.

High-speed videos show that after the keyhole bottom, this emerging flow levels off to a height that defines a section through which all the melt generated by the welding process must flow (corresponding to cut (a) in Fig. 8.9(a)). This emerging flow is kept pressed along the bottom of this groove on a distance of about $1 \mathrm{~mm}$; it is probably deflected by the melt ejected sideways at high velocity from the keyhole front. Then, at a certain distance, a central part of this flow is detached and generates a thin vertical strip of liquid jet (corresponding to cut (c) in Fig. 8.9(a)) that will undergo the Rayleigh instability leading to humping (Rayleigh, 1892, Gratzke et al., 1992).

From the cross-section measurements at the different locations (see Fig. 8.9), one can estimate the various flow speeds involved and examine the relevance of the previous model. The cross-section of solid material melted by the inclined keyhole front is $S_{\text {in }}$ (see Fig. 8.9(d)). With a welding speed $\mathrm{V}_{\mathrm{w}}$, the flow rate of melted material generated by the process is then $S_{\mathrm{in}} \cdot \mathrm{V}_{\mathrm{w}}$ (in $\mathrm{m}^{3} / \mathrm{s}$ ). If the cross-sections of the flow, defined from the melted zone at the locations ' $a$ ' and ' $c$ ' of Fig. 8.9(a), are respectively $S_{a}$ and $S_{c}$, the mean local melt speed will be multiplied by the ratio $S_{\text {in }} / S_{a}$ and $S_{\text {in }} / S_{c}$, compared to the welding speed $\mathrm{V}_{\mathrm{w}}$. Figure 8.9(c) and 8.9(d) show corresponding transverse cross-sections, for a welding speed of $20 \mathrm{~m} / \mathrm{min}$. The ratio $\mathrm{S}_{\mathrm{in}} / \mathrm{S}_{\mathrm{c}}$ is then estimated to about 1.7-2 here. Therefore the melt speed inside the thin strip of melt jet is very high, and typically reaches $40 \mathrm{~m} / \mathrm{min}$, in the laboratory frame, for these operating conditions.

Note: the cross-section of melt pool at position ' $a$ ' (labelled cut ' $a$ ' of Fig. 8.9(a)) cannot be determined after the end of the laser welding because this part of the melt flow disappears just after switching the laser off, due to its very high rearwards speed. Only a transverse cut at position ' $c$ ' near and in front of the last hump, or between them, can be estimated. An example of the keyhole front shape obtained after switching off the laser is shown in Fig. 8.9(e). It is used to define the surface $S_{\text {in }}$ shown on Fig. 8.9(d). The 3 -D shape of the keyhole front wall can be clearly observed and analyzed. It corresponds exactly to the shape observed during the interaction, because the flow here is very high with a very thin melt thickness; so thermal load is negligible and the keyhole front shape does not evolve after switching off the laser. 
Concerning hump dynamics, we observe that a hump has a final volume $\Delta \mathrm{V}$ and is fed during a time $\tau$. It has a characteristic ellipsoid volume, with a length $\mathrm{L}$ and diameter $\mathrm{D}$ that are respectively 1.3 and $0.55 \mathrm{~mm}$, for the previous operating conditions (see Fig. 8.9(b)). Video movies show that the time between two consecutive constrictions of the strip melt jet defines a typical feeding time $\tau$ of about $7 \mathrm{~ms}$. Therefore the corresponding mean feeding flow rate of the hump $\Delta \mathrm{V} / \tau$ is about $0.03 \mathrm{~mm}^{3} / \mathrm{ms}=310^{-8} \mathrm{~m}^{3} / \mathrm{s}$. This flow rate has first to be compared with the incoming flow rate $S_{\text {in }} \cdot V_{w}$ $=0.24 \cdot 0.33 \mathrm{~mm}^{3} / \mathrm{ms}=810^{-8} \mathrm{~m}^{3} / \mathrm{s}$ generated at the keyhole front. Due to the relative motion of the melt flow with the sample moving at $V_{w}$, it is easy to show that the flow rate in the sample frame is about half of the incoming one, which is then typically equal to $410^{-8} \mathrm{~m}^{3} / \mathrm{s}$. These two values of the feeding rates being in agreement, one can consider that this scheme of hump formation is consistent.

An interesting observation on this mechanism concerns the possibility of reducing or even suppressing the humping phenomena by decelerating the ejected melt flow. This can easily be obtained by also using a nozzle placed in the 'rear jet position' (see Fig. 8.14(a)), whose gas jet interacts with the melt flow emerging from the bottom of the keyhole. With adapted Argon gas flow emitted by the nozzle (typically about $15 \mathrm{l} / \mathrm{min}$ ), one can slow down the melt flow that fills up the groove and humping is then suppressed.

One must emphasize here that the humping process observed during these experiments, where rather large focal spots are used, is consistent with the humping behaviour usually observed during arc welding process (Mendez and Eagar, 2003). This humping results from hydrodynamic effects, with melt flows at very high mean speeds, where Rayleigh instability occurs on these liquid jets. We have seen that for this regime, the vapour plume does not interact with the melt, contrary to the four previous regimes due to the inclination of vapour plume. One must add that this humping is totally different from the humping observed in experiments using smaller focal spots obtained with high beam quality lasers (Behler and Schäfer, 2005, Myamoto et al., 2004). In that case, periodic perturbations of weld seam are also observed but at rather low welding speeds; regular droplets are deposited along the seam but without the characteristic undercuts. Moreover, the corresponding penetration depths and aspect ratio (depth/diameter) are more important than for the 'hydrodynamic' humping described here. This 'capillary' humping probably results from the particular melt dynamics around the keyhole emitted from deeper regions to the top of the weld bead, where friction effects of ejected plume may be important even at higher welding speeds (due to the small keyhole diameter). It would rather correspond to some 'single wave regime', but for operating conditions leading to rather deep penetrations. It is clear that a better understanding of these mechanisms needs similar complete analysis for these rather different new conditions. 


\subsection{Conclusions}

This set of experiments has allowed analysis for various conditions of the geometry of the keyhole front, the direction and the dynamic pressure of ejected vapour plume, the 3D geometry of the melt pool surface. Their interpretation has led us to the conclusion that the interaction of this vapour plume with the melt pool is a very efficient way to generate or modify its hydrodynamics that is initially defined by the side flows of melt generated underneath the focal spot by the local 'piston effect'. It is the inclination of the keyhole front wall and the dynamic pressure of the corresponding ejected vapour plume that controls the level of coupling between the vapour plume and melt pool. This coupling can result from induced friction stresses of vapour flowing along the walls inside a quite vertical keyhole at low welding speeds, or from a direct collision of the vapour with the keyhole rear wall generating strong melt pool perturbations for higher welding speeds. Finally above a critical welding speed, the important evaporation pressure accelerates efficiently a liquid jet that undergoes the humping instability.

The previous experiments have been realized with a rather large focal spot $(0.45$ and $0.6 \mathrm{~mm})$ compared to those that become achievable with recent advent of high beam quality lasers, which are thus able to deliver intensities more than one order of magnitude greater. We have seen the importance of the keyhole front wall inclination in the triggering of these different regimes. As we know that this inclination is a monotonic function of the ratio of welding speed to the incident intensity, similar regimes with these high beam quality lasers should also be observed, but at much higher welding speeds. Recent experiments with these high beam quality lasers have already shown that critical welding speeds for the 'melt flow dynamic' humping process was largely increased (Behler and Schäfer, 2005, Myamoto et al., 2004). So, future corresponding detailed experiments will be welcomed for confirmation and extension to the new range of operating parameters.

These various experiments have therefore emphasized the importance and the complexity of melt pool hydrodynamics during laser welding. Obviously, if one wants a correct description of the melt pool and beyond it, the final weld seam geometry, particularly at high welding speeds, it is necessary to master 3D simulations dealing with free surface problems. Moreover, if one wants to take into account the complete mechanisms driven by the vapour plume, it is also necessary to describe the vapour/free surface interaction, which is a very complex problem for numerical simulations (Amara et al., 2006).

\subsection{References}

Aalderink B J, de Lange D F, Aarts R G K M and Meijer J (2007), 'Keyhole shapes during laser welding of thin metal sheets', J Phys D Appl Phys, 40, 5388-5393. 
Amara E H, Fabbro R and Hamadi F (2006), 'Modelling of the melted bath movement induced by the vapour flow in deep penetration laser welding', J Laser Appl, 18(1), $2-11$.

Beck M (1996), Modellierung des Lasertiefschweissens B. G. Teubner Stuttgart ISBN 3-519-06218-6.

Behler K and Schäfer P (2005), 'Melt pool dynamics in high speed welding with modern high power solid state lasers', in Proceedings of the ICALEO'2005 Conference, Miami, USA, Oct. 31-Nov. 3, 1026-1031.

Bergström D, Powell J and Kaplan A (2007), 'Nd:Yag laser absorptance by rough metal surfaces', Proceedings ICALEO'2007 October 29-November 1, Orlando USA, p. 704-713, paper 1804.

Carslaw H S and Jaeger J C (1962), Conduction of heat in solids, 2nd Edition (Oxford: Clarendon).

Dausinger F, Berger P and Hügel H (2002), 'Laser welding of aluminum alloys: Problems, approaches for improvement and applications', Proceedings of ICALEO Conference, (Scottsdale, USA), LIA Editors.

Fabbro R (2002), 'Basic processes in deep penetration laser welding', in Proceedings of the ICALEO'2002 Conference, Scottsdale, USA Oct. 14-17.

Fabbro R and Chouf K (2000a), 'Keyhole modeling during laser welding', J Appl Phys, 87(9), 4075-4083.

Fabbro R and Chouf K (2000b), 'Dynamical description of the keyhole in deep penetration laser welding', J Laser Appl, 12, 142-148.

Fabbro R, Hamadou M and Coste F (2004), 'Metallic vapour ejection effect on melt pool dynamics in deep penetration laser welding', J Laser Appl, 16(1), 16-19.

Fabbro R, Slimani S, Coste F and Briand F (2005), 'Study of keyhole behaviour for full penetration Nd-Yag CW laser welding', J Phys D Appl Phys, 38, 1881-1887.

Fabbro R, Coste F, Goebels D and Kielwasser M (2006a), 'Study of CW Nd-Yag laser welding of Zn-coated steel sheets', J Phys D: App Phys, 39, 401-409.

Fabbro R, Slimani S, Doudet I, Coste F and Briand F (2006b), 'Experimental study of the dynamical coupling between the induced vapour plume and the melt pool for Nd-Yag laser welding', J Phys D: App Phys, 39, 394-400.

Fabbro R, Slimani S, Coste F, Briand F, Dlubak B and Loisel G (2006c), 'Analysis of basic processes inside the keyhole during deep penetration Nd-Yag CW laser welding', in Proceedings of ICALEO'2006 Conference, Scottsdale, USA (Oct. 30-Nov. 2).

Fabbro R, Slimani S, Coste F and Briand F (2007a), 'Analysis of the various melt pool hydrodynamic regimes observed during CW Nd-Yag deep penetration laser welding', in Proceedings of the ICALEO'2007 Conf., Orlando, USA, (Oct. 29-Nov. 1).

Fabbro R, Slimani S, Coste F and Briand F (2007b), 'Experimental study of the humping process during Nd:Yag CW laser welding', in Proceedings of the LIM Conference, Munich, Germany, June 17-22, 18-21.

Furich T, Berger P and Hügel H (2001), 'Marangoni effect in laser deep penetration welding of steel', J Laser Appl, 13, 178-186.

Gratzke U, Kapadia P D, Dowden J, Kroos J and Simon G (1992), ‘Theoretical approach to the humping phenomenon in welding processes', J Phys D: Appl Phys, 25, 1640-1647.

Hohenberger B, Chang C, Schinzel C, Dausinger F and Hügel H (1999), 'Laser welding with Nd:Yag multi-beam technique', Proceedings ICALEO’1999, 87, D167-176.

Kamikuki K, Inoue T, Yasuda K, Muro M, Nakabayashi T and Matsunawa A (2002), 'Prevention of welding defect by side gas flow and its monitoring method in continuous wave ND:Yag laser welding', J Laser Appl, 14, 136-145. 
Katayama S, Seto N, Mizutani M and Matsunawa A (2000), 'Formation mechanism of porosity in high power Yag laser welding', in Proceedings of ICALEO'2000 Conference, Dearborn, USA, Section C, 16-25.

Kern M, Berger P and Hügel H (2000), 'Magneto-fluid dynamic control of seam quality in $\mathrm{CO}_{2}$ laser beam welding', Welding $J, 79,72-80$.

Ki H, Mohanty P S and Mazumder J (2002), 'Multiple reflection and its influence on keyhole evolution', J Laser Appl, 14, 39-45.

Kinoshita K, Mizutani M, Kawahito Y and Katayam S (2006), 'Phenomena of welding with high-power fiber laser', in Proceedings of ICALEO'2006 Conference, October 30-November 2, Scottsdale, USA, 535-542.

Kroos J, Gratzke U, Vicanek M and Simon G (1993), 'Dynamic behaviour of the keyhole in laser welding', $J$ Phys D App Phys, 26, 481-486.

Matsunawa A and Semak V (1997), 'The simulation of front keyhole wall dynamics during laser welding', J. Phys. D, 30, 798-809.

Matsunawa A, Kim J D, Seto N Mizutani M and Katayama S (1998), 'Dynamics of keyhole and molten pool in laser welding' J. Laser Appl., 1, 247-254 (and references herein).

Mendez P F and Eagar T W (2003), 'Penetration and defect formation in high-current arc welding', Welding Research J. 82(10), 296-S to 306-S.

Myamoto I, Park S J and Ooie T (2004), 'High- speed microwelding by single-mode fiber laser', in Proceedings of the 4th LANE'2004 Conf., Erlangen, Germany, 55-66.

Petring D (1995), Anwendungsorientierte Modellierung des Laserstrahlschneidens zur rechnergestüzten Prozessoptimierung, Verlag Shaker, Aachen, ISBN 3-8265-043$3 \mathrm{X}$.

Rayleigh J W S (1892), 'On the instability of a cylinder of viscous liquid under capillary force', Philos. Mag. 34, 177-184.

Semak V and Matsunawa A (1997), 'The role of recoil pressure in energy balance during laser materials processing', J Phys D:Appl, Phys, 30, 2541-2552.

Sudnik W, Radaj D, Breitschwerdt S and Erofeew W (2000), 'Numerical simulation of weld pool geometry in laser beam welding', $J$ Phys $D, 33,662-671$.

Thomy C, Seefeld T, Wagner F and Vollertsen F (2006), 'Humping in welding with single mode fiber lasers', (2006), in Proceedings of the ICALEO'2006 Conference, Scottsdale, USA, Oct. 30-Nov. 2, 543-552.

Tsukamoto S, Kawaguchi I, Arakane G and Honda G H (2001), 'Suppression of porosity using pulse modulation of laser power in $20 \mathrm{~kW} \mathrm{CO}$ laser welding', in Proceedings of ICALEO'2001 Conference, Jacksonville, USA, D607-615.

Von Allmen M et al. (1976), 'Laser drilling in metals', J Appl Phys, 47, 5460-5463.

Zang W H and Tsai H L (2002), 'Numerical modeling of keyhole dynamics' Proceedings LAMP'2002 May 21-31, Osaka

\subsection{List of symbols}

A: $\quad$ Atomic mass of material $(\mathrm{kg})$

$\mathrm{A}(\alpha)$ : Angular dependence of absorptivity

$\mathrm{A}_{0}: \quad$ Absorptivity under normal incidence

B: $\quad$ Slope $(\mathrm{J} / \mathrm{m})$

D: $\quad$ Spot diameter $(\mathrm{m})$ 


$\begin{array}{ll}\mathrm{I}_{\mathrm{abs}}: & \text { Absorbed intensity }\left(\mathrm{W} / \mathrm{m}^{2}\right) \\ \mathrm{I}_{0}: & \text { Incident intensity }\left(\mathrm{W} / \mathrm{m}^{2}\right) \\ \mathrm{I}_{\text {cond }}: & \text { Conduction loss inside solid }\left(\mathrm{W} / \mathrm{m}^{2}\right) \\ \mathrm{k}: & \text { Constant }\left(\mathrm{m}^{3} \mathrm{~J}^{-1}\right) \\ \mathrm{L}: & \text { Keyhole depth }(\mathrm{m}) \\ \mathrm{L}_{\mathrm{v}}: & \text { Enthalpy of evaporation }(\mathrm{J} / \mathrm{kg}) \\ \mathrm{m}: & \text { Mass ablation rate due to evaporation process }\left(\mathrm{kg} /\left(\mathrm{m}^{2} . \mathrm{s}\right)\right. \\ \mathrm{P}: & \text { Incident laser power }(\mathrm{W}) \\ \mathrm{P}_{\mathrm{d}}: & \text { Dymanical pressure of ejected vapour plume }\left(\mathrm{N} / \mathrm{m}^{2}\right) \\ \mathrm{P}_{\mathrm{evap}}: & \text { Evaporation pressure }\left(\mathrm{N} / \mathrm{m}^{2}\right) \\ \mathrm{P}_{\mathrm{m}}: & \text { Melt dynamical pressure }\left(\mathrm{N} / \mathrm{m}^{2}\right) \\ \mathrm{P}_{\mathrm{s}}: & \text { Surface tension pressure }\left(\mathrm{N} / \mathrm{m}^{2}\right) \\ \mathrm{R}: & \text { Perfect gas constant }(\mathrm{J} / \mathrm{K}) \\ \mathrm{S}_{\mathrm{a}}, \mathrm{S}_{\mathrm{in}}, \mathrm{S}_{\mathrm{c}}: & \text { Cross-sections of weld seam at different locations }\left(\mathrm{m}^{2}\right) \\ \mathrm{T}_{\mathrm{v}}: & \text { Evaporation temperature of material }(\mathrm{K}) \\ \mathrm{U}_{0}: & \text { Induced upward melt velocity }(\mathrm{m} / \mathrm{s}) \\ \mathrm{V}_{\mathrm{c}}: & \text { Closing speed of keyhole }(\mathrm{m} / \mathrm{s}) \\ \mathrm{V}_{\mathrm{c}}: & \text { Rear keyhole wall velocity }(\mathrm{m} / \mathrm{s}) \\ \mathrm{V}_{\mathrm{d}}: & \text { Drilling velocity }(\mathrm{m} / \mathrm{s}) \\ \mathrm{V}_{\mathrm{g}}: & \text { Mean velocity of ejected vapour plume }(\mathrm{m} / \mathrm{s}) \\ \mathrm{V}_{\mathrm{m}}: & \text { Melt ejection velocity }(\mathrm{m} / \mathrm{s}) \\ \mathrm{V}_{\mathrm{w}}: & \text { Welding speed (m/s) } \\ \alpha: & \text { Inclination angle of the keyhole front wall }(\mathrm{rd}) \\ \Delta \mathrm{P}: & \text { Net pressure on keyhole wall }\left(\mathrm{N} / \mathrm{m}^{2}\right) \\ \Delta \mathrm{V}: & \text { Volume of a hump }\left(\mathrm{m}^{3}\right) \\ \rho_{\mathrm{g}}: & \text { Vapour plume density }\left(\mathrm{kg} / \mathrm{m}^{3}\right) \\ \eta_{\mathrm{g}}: & \text { Dynamic viscosity of vapour plume }(\text { Pa.s }) \\ \eta_{\mathrm{m}}: & \text { Dynamic viscosity of melt }(\mathrm{Pa} . \mathrm{s}) \\ \sigma: & \text { Surface tension coefficient }(\mathrm{N} / \mathrm{m}) \\ \tau: & \text { Feeding time of a hump }(\mathrm{s}) \\ \tau_{\mathrm{g}}: & \text { Shear stress of vapour plume along keyhole wall }\left(\mathrm{N} / \mathrm{m}^{2}\right) \\ & \end{array}$

